\title{
EGFR and HER2neu Expression in Gall Bladder Carcinoma and Its Association with Clinicopathological Parameters - An Institutional Experience from North India
}

\author{
Inara Abeer', Sabina Khan ${ }^{1}$, Mohd. Jaseem Hassan², Musharraf Hussain ${ }^{3}$
}

${ }^{1}$ Department of Pathology, Hamdard Institute of Medical Sciences \& Research Jamia Hamdard, New Delhi, India. ${ }^{2} \mathrm{JN}$ Medical College, AMU, Aligarh, India. ${ }^{3}$ Department of Surgery, Hamdard Institute of Medical Sciences \& Research Jamia Hamdard, New Delhi, India.

\begin{abstract}
Objective: Gallbladder cancer (GBC) is the most common biliary tract malignancy found worldwide with very high incidence in North India especially Delhi region. It is characterized by poor prognosis and ineffective treatment especially in advanced stage. The aim of this study was to evaluate EGFR and HER2/neu immunoexpression in cancer patients and to correlate it with the clinicopathological parameters so as to identify GBC patients who can benefit from targeted therapy. Methods: Present study was conducted in the Department of Pathology, Hamdard Institute of Medical Sciences \& Research, New Delhi. A total of 40 cases of Gallbladder carcinoma (GBC) were evaluated for Immunohistochemical expression of EGFR and HER2/neu. Clinicopathological parameters of GBC were studied and correlated with immunoexpression of EGFR and HER2 /neu. Result: The mean age of the GBC patients was 55.9 years with $90 \%$ being females. On histopathology, 34(85\%) cases were conventional adenocarcinoma. The EGFR expression was positive in 29/40 cases (72.5\%). It was significantly more positive in poorly differentiated grade and advanced stages of gall bladder carcinoma $(\mathrm{P}<0.05)$. The expression of HER2/ neu was positive in $13 / 40$ cases $(32.5 \%)$. It was significantly more positive in well differentiated gall bladder carcinoma $(\mathrm{P}<0.05)$. Immunoexpression of EGFR was inversely related with $\mathrm{HER} 2 /$ neu expression and this association was statistically significant. Conclusion: Among GBC patients, EGFR expression and HER2/neu expression was $72.5 \%$ and $32.5 \%$, respectively. Significant EGFR expression was seen in poorly differentiated and advanced stage cancers while significant HER2/neu expression was seen in well differentiated gall bladder carcinomas. To conclude, these two markers HER2/neu and EGFR can be used as predictive and prognostic markers respectively, with rationale to further explore the use of anti-HER2 and anti- EGFR therapy in gall bladder cancer.
\end{abstract}

Keywords: Gall bladder carcinoma- EGFR- HER2/neu

Asian Pac J Cancer Biol, 6 (1), 57-65

\section{Introduction}

Gallbladder cancer is the most common and highly lethal malignancy of the biliary tract worldwide. A very high incidence of this cancer is reported from North India, Chile, Japan and Korea roughly correlating with higher incidence of cholelithiasis in these regions [1]. Relatively lower incidence levels are seen in many western countries. [2]. The worldwide occurrence of gallbladder cancer is less than 2/100000 individuals, but this has been recorded
Submission Date: 07/31/2020Ａcceptance Date: 02/28/2021

\footnotetext{
Corresponding Author:

Dr. Sabina, Khan

Department of Pathology, Hamdard Institute of Medical Sciences \& Research Jamia Hamdard, New Delhi, India.

Email: drsabina1@gmail.com
} 
and lack of selective screening tests for early detection resulting in delayed diagnosis at advanced stage.

Surgery is the only curative therapy for gallbladder cancer. However, at diagnosis, less than $10 \%$ of the patients are candidate for curative surgery [4]. The role of adjuvant therapy in GBC is not well defined. Systemic chemotherapy has shown modest survival benefit in the management of advanced gallbladder cancer. However, available cytotoxic drugs have poor response rate.

Currently, targeted therapy has limited role in the management of gallbladder cancer. Common mutations reported in gallbladder cancer are KRAS, EGFR, BRAF and ERBB2/HER2-neu [5]. Early data suggests possible benefit from blockade of the epidermal growth factor receptor (EGFR) by the oral tyrosine kinase inhibitor erlotinib or anti-EGFR monoclonal antibody cetuximab. [6]. The role of HER2/neu expression in gallbladder cancer and targeting this receptor in the management of gallbladder cancer has also been an area of recent research. There are very few reports in the literature especially in the Indian context regarding EGFR and HER2/neu expression in gallbladder carcinoma (GBC). Thus, our study aims to explore the immunohistochemical expression of EGFR and HER2/neu in gallbladder cancer patients and its correlation with clinicopathological parameters so as to identify their role as potential molecular targets for diagnosis and treatment of GBC.

\section{Materials and Methods}

The present cross-sectional study was conducted in the Department of Pathology, Hamdard Institute of Medical Science and Research Hakeem Abdul Hameed Centenary Hospital, New Delhi from June 2017 to August 2019. Ethical clearance was taken from the Institutional Ethics Committee.

A total of 40 cases of histopathologically diagnosed Gallbladder carcinoma were included in the study. Patients with any other associated malignancy or with prior treatment in any form (surgery/radiotherapy/ chemotherapy) were excluded.

The resected cholecystectomy specimens were fixed in $10 \%$ buffered formalin and tissue-embedded paraffin blocks prepared using routine procedures. Haematoxylineosin staining was done and various histopathological parameters were evaluated. Staging of Gall bladder carcinoma was done according to the TNM staging system for carcinomas of the gallbladder of the American Joint Committee on Cancer (AJCC) and the International Union Against Cancer (UICC) (AJCC/UICC TNM, $7^{\text {th }}$ edition) [7].

Immunohistochemistry (IHC) for EGFR (Anti-human EGFR rabbit monoclonal antibody, clone EP22, Master Diagnostica, Spain) and HER2/neu (Anti-cERBB2 rabbit monoclonal antibody, clone SP3, Master Diagnostica, Spain) was performed according to the following procedure:

\section{IHC Procedure}

Four to five-micron thick paraffin sections were taken on poly-1-lysine coated slides. Following deparaffinization, slides were placed in citrate buffer and antigen retrieval done by heat method. After washing with distilled water for one to two minutes, followed by tris buffer for one minute, Peroxidase blocking was done using hydrogen peroxide for fifteen minutes.

Slides were then incubated with Primary antibody i.e. EGFR and HER2/neu respectively. Primary antibody was put on the slides one by one and kept for 30 minutes each. Slides washed with Tris buffer again for one to two minutes. Slides were incubated with Secondary antibody (HRP-conjugate) for another thirty minutes followed by washing with buffer for one to two minutes. These slides were incubated in freshly prepared chromogen DAB (3, 3 '-diaminobenzidine tetra hydrochloride) for five minutes and stopped with tap water. Slides were counterstained with Harris Haematoxylin followed by washing and air dried. Then the slides were mounted with DPX.

\section{Immunohistochemical evaluation}

Cell membrane staining was used to assess positivity for both the markers. HER2/neu and EGFR positivity was defined according to the CAP/ASCO (College of American Pathologists/American Society of Clinical Oncology) criteria for breast cancer, given their wide acceptance in scientific literature.

Immuno-staining classification was based on staining intensity \& percentage of stained cells [8].

\section{Interpretation and immuno-scoring}

We divided the IHC reporting into 4 grades as follows:

IHC 0: No staining is observed or Membrane staining that is incomplete and is faint/barely perceptible and within $\leq 10 \%$ of tumour cells.

IHC 1+: Incomplete membrane staining that is faint/ barely perceptible and within $>10 \%$ of tumour cells.

IHC 2+: Circumferential membrane staining that is incomplete and/or weak/moderate and within $>10 \%$ of tumour cells or Complete and circumferential membrane staining that is intense and within $\leq 10 \%$ of tumour cells.

IHC 3+: Circumferential membrane staining that is complete, intense, and within $>10 \%$ of tumour cells.

For the scoring of HER2/neu protein and EGFR expression, only the membrane staining intensity and pattern were evaluated. Score of $2+$ and $3+$ were taken as positive.

\section{Results}

A total of 2084 cholecystectomy specimens were received during the study period, out of which 40 cases $(1.6 \%)$ were histopathologically diagnosed as gallbladder carcinoma. The age of the patients ranged from 21 to 86 years with mean age being 55.9 years. A strong female preponderance was seen with $90 \%$ being females. There was strong family history of GBC in 5 patients $(12.5 \%$ cases). The presenting symptoms were commonly nausea (97.5\%) followed by pain in right upper abdomen (77.5\%). Clinically, only $11(27.5 \%)$ patients were preoperatively diagnosed as carcinoma gall bladder and rest of the 29 
Table 1. Clinical Profile of Study Population

\begin{tabular}{|c|c|c|}
\hline Characteristics & $\begin{array}{c}\text { Number of } \\
\text { cases }\end{array}$ & $\begin{array}{c}\text { Percentage } \\
(\%)\end{array}$ \\
\hline \multicolumn{3}{|l|}{ Age } \\
\hline Mean \pm S.D. & \multicolumn{2}{|c|}{$55.5 \pm 13.1$} \\
\hline Median & \multicolumn{2}{|c|}{55} \\
\hline \multicolumn{3}{|l|}{ Gender distribution } \\
\hline Male & 4 & 10 \\
\hline Female & 36 & 90 \\
\hline \multicolumn{3}{|l|}{ Family History } \\
\hline Present & 5 & 12.5 \\
\hline Absent & 35 & 87.5 \\
\hline \multicolumn{3}{|l|}{ Presenting symptoms } \\
\hline Pain Right upper abdomen & 31 & 77.5 \\
\hline Nausea & 39 & 97.5 \\
\hline Vomiting & 11 & 27.5 \\
\hline Dyspepsia & 21 & 52.2 \\
\hline Loss of appetite & 16 & 40 \\
\hline Weight loss & 11 & 27.5 \\
\hline Fever & 17 & 42.5 \\
\hline Obstructive Jaundice & 2 & 5 \\
\hline \multicolumn{3}{|l|}{ Clinical Diagnosis } \\
\hline Carcinoma gall bladder & 11 & 27.5 \\
\hline Incidental & 29 & 72.5 \\
\hline \multicolumn{3}{|l|}{ Ultrasound findings } \\
\hline \multicolumn{3}{|l|}{ Stone } \\
\hline Present & 40 & 100 \\
\hline Absent & - & - \\
\hline \multicolumn{3}{|l|}{ Wall thickness } \\
\hline $0-3 \mathrm{~mm}$ & 13 & 32.5 \\
\hline$>3 \mathrm{~mm}$ & 27 & 67.5 \\
\hline
\end{tabular}

(72.5\%) cases were diagnosed incidentally (Table 1$)$.

On Ultrasound (USG), gallstones were present in all the 40 cases of GBC and gallbladder wall was thickened in $67.5 \%$ cases. Laparoscopic cholecystectomy was done in $22(55 \%)$ cases followed by open cholecystectomy in $11(27.5 \%)$ cases. In rest of the 7 cases, laparoscopy was converted into open cholecystectomy due to adhesions or difficult dissection. Per-operatively localized mass was seen in only $7.5 \%$ cases.

On gross examination, gall bladder wall was thickened in $72.5 \%$ cases with $50 \%$ of these cases showing diffusely thickened wall. Histopathologically, 34 (85\%) cases were conventional adenocarcinoma (Figure 1A, B) with other variants being papillary, adenosquamous, and squamous carcinoma. Most of them were moderately differentiated $(57.5 \%)$ followed by well differentiated $(30 \%)$ and poorly differentiated in $12.5 \%$ of the cases. On pathological staging, most of the cases were seen in stage pT1b (17 cases).Nodes were received in 16 out of 40 cases and were positive in $18.8 \%$ cases. Liver bed was involved in $27.3 \%$ cases. Out of 40 cases, perineural invasion was seen in 8 cases $(20 \%)$ and lymphovascular invasion was seen in 12 cases $(30 \%)$ (Table 2 ) In our study population, Early (pT1a, pT1b) and advanced (pT2, pT3) stage disease were noted in $57.5 \%$ and in $42.5 \%$, cases respectively.

Immunohistochemistry was done with EGFR and HER2/ neu on all 40 cases of GBC. EGFR immunoexpression was present in $29(72.5 \%)$ cases and negative in $11(27.5 \%)$ cases. EGFR expression was more in moderately ( 20 cases) and poorly ( 5 cases) differentiated cancers (Figure 2A,B) with lesser expression in well differentiated cancers thus showing a parallel increase with the increase in histological grade and this association was found to be significant $(p=0.001)$ EGFR overexpression was also positive in advanced stages of gall bladder carcinoma ( $16 / 17$ cases; $42.5 \%)$; thus showing significant association with histological grade and advanced stage of the cancer $(\mathrm{P}<0.05)$. However, there was no significant association of EGFR expression with histopathological types, pathological stage, Lymph node status, peri-neural invasion, lymphovascular invasion and liver involvement $(\mathrm{P}>0.05)$ (Table 3).

The expression of HER2/neu was positive in 13 $(32.5 \%)$ cases and negative in $27(67.5 \%)$ cases. It was significantly more positive in well differentiated gall bladder carcinoma i.e. $69.2 \%$ cases while all the 5
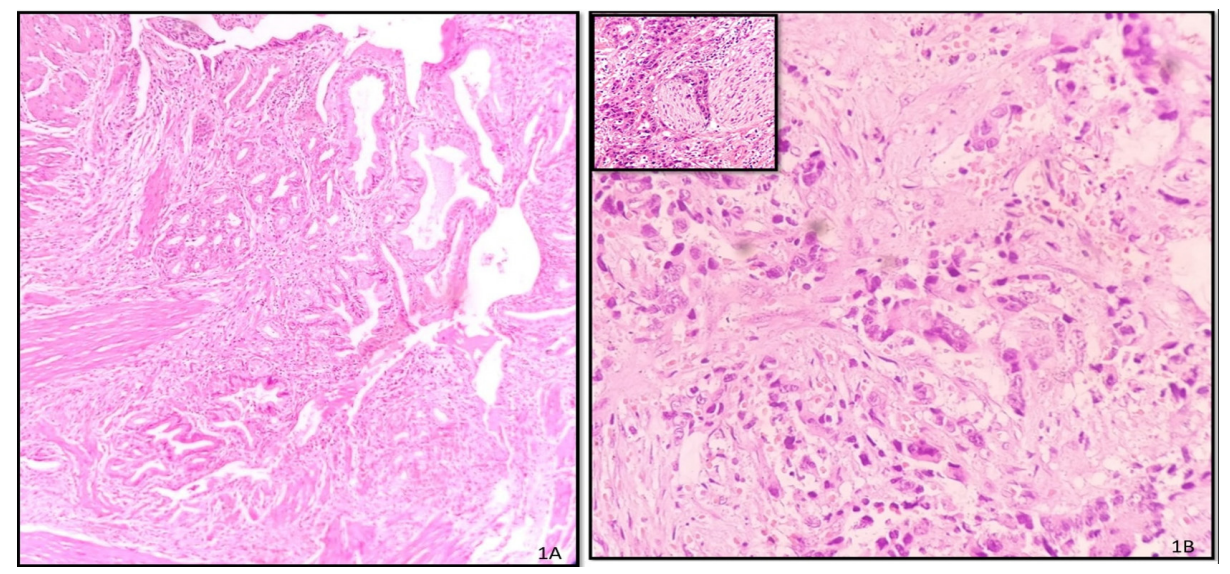

Figure 1. A, Well-differentiated Adenocarcinoma Composed of Malignant Glands Infiltrating the Muscle Layer of the Gallbladder (H\&E, 10X); B, Poorly differentiated Adenocarcinoma of the gallbladder showing cords and singly dispersed malignant cells (H\&E, 10X), inset showing perineural invasion (H\&E, 40X) 
Table 2. Histopathological Characteristics of Cases of Gall Bladder Carcinoma

\begin{tabular}{|c|c|c|c|}
\hline & & \multicolumn{2}{|c|}{ Cases } \\
\hline & & Number of cases & Percentage $(\%)$ \\
\hline \multicolumn{4}{|l|}{ Histopathological Type } \\
\hline Conventional Adenocarcinoma & & 34 & 85 \\
\hline Papillary Adenocarcinoma & & 1 & 2.5 \\
\hline Adenosquamous carcinoma & & 1 & 2.5 \\
\hline Squamous cell carcinoma & & 2 & 5 \\
\hline Adenocarcinoma with xanthogranulomatous cholecystitis & & 2 & 5 \\
\hline \multicolumn{4}{|l|}{ Histopathological Grade } \\
\hline Well differentiated (G1) & & 12 & 30 \\
\hline Moderately differentiated (G2) & & 23 & 57.5 \\
\hline Poorly differentiated (G3) & & 5 & 12.5 \\
\hline \multicolumn{4}{|l|}{ Pathological Stage } \\
\hline pT1a & & 6 & 15 \\
\hline $\mathrm{pT} 1 \mathrm{~b}$ & & 17 & 42.5 \\
\hline pT2 & & 11 & 27.5 \\
\hline pT2N1 & & 2 & 5 \\
\hline pT3 & & 3 & 7.5 \\
\hline pT3N1 & & 1 & 2.5 \\
\hline \multirow[t]{2}{*}{ Nodal Status (16 cases) } & Positive & 3 & 18.6 \\
\hline & Negative & 13 & 81.4 \\
\hline \multirow[t]{2}{*}{ Liver bed(11 cases) } & Involved & 3 & 27.3 \\
\hline & Uninvolved & 8 & 72.7 \\
\hline \multirow[t]{2}{*}{ Peri-neural invasion } & Present & 8 & 20 \\
\hline & Absent & 32 & 80 \\
\hline \multirow[t]{2}{*}{ Lympho-vascular invasion } & Present & 12 & 30 \\
\hline & Absent & 28 & 70 \\
\hline \multirow[t]{2}{*}{ Early and advanced stage cancer } & Early & & 57.5 \\
\hline & Advanced & & 42.5 \\
\hline
\end{tabular}

poorly differentiated cases were immunonegative for HER2/neu (Figure 3A, B); thus, showing significant association with histological grade $(\mathrm{P}<0.05)$. There was no significant association between HER2/neu expression and histopathological types, pathological stage, lymph node status, peri-neural invasion, lymphovascular invasion, liver involvement and advanced stages of gall bladder carcinoma. ( $\mathrm{P}>0.05)$ (Table 4) In our study intratumoral heterogenicity was also seen in 3 out of the 13 HER2/neu positive cases (Figure 4).

Out of the 40 cases, 4 cases showed co-expression of EGFR and HER2/neu while both showed immunonegativity in only 2 cases; 25 cases were EGFR positive but HER2/neu negative; while 9 cases were HER2/neu positive but EGFR negative. EGFR expression was seen more in the advanced as compared to the early stage GBC and was statistically significant while HER2/ neu expression was more in the early stage of GBC although this association was not found to be significant. Thus, the immunoexpression of EGFR was inversely related with HER2/neu expression and this association was statistically significant $(\mathrm{P}<0.05)$ (Figure 5).

\section{Discussion}

GBC is a highly malignant neoplasm characterized by delayed diagnosis, poor prognosis and ineffective treatment especially in advanced stages. As per the GLOBOCAN 2018 data, [9] about 219,000 people were estimated to have been diagnosed with GBC which constitutes $1.2 \%$ of all cancer diagnoses. It accounts for about 165,000 cancer deaths annually, which is $1.7 \%$ of all global cancer deaths. The role of radiation, chemoradiation and chemotherapy in neoadjuvant and adjuvant settings in GBC is not well defined. In order to develop targeted therapy for GBC it is very essential to understand various molecular alterations involved in the pathogenesis of cancer. A number of recent studies have identified ERBB2 signalling as the most frequently mutated pathway in GBC. EGFR and HER2/neu are members of the ERBB2 receptor tyrosine kinase family. However, their exact role in the pathogenesis of GBC is not yet fully understood.

A total of 2084 Cholecystectomy specimens were received in our department during the study period; with $1.9 \%$ incidence of Gallbladder cancer. The incidence of GBC is more in elderly females (2-6 times) in comparison 

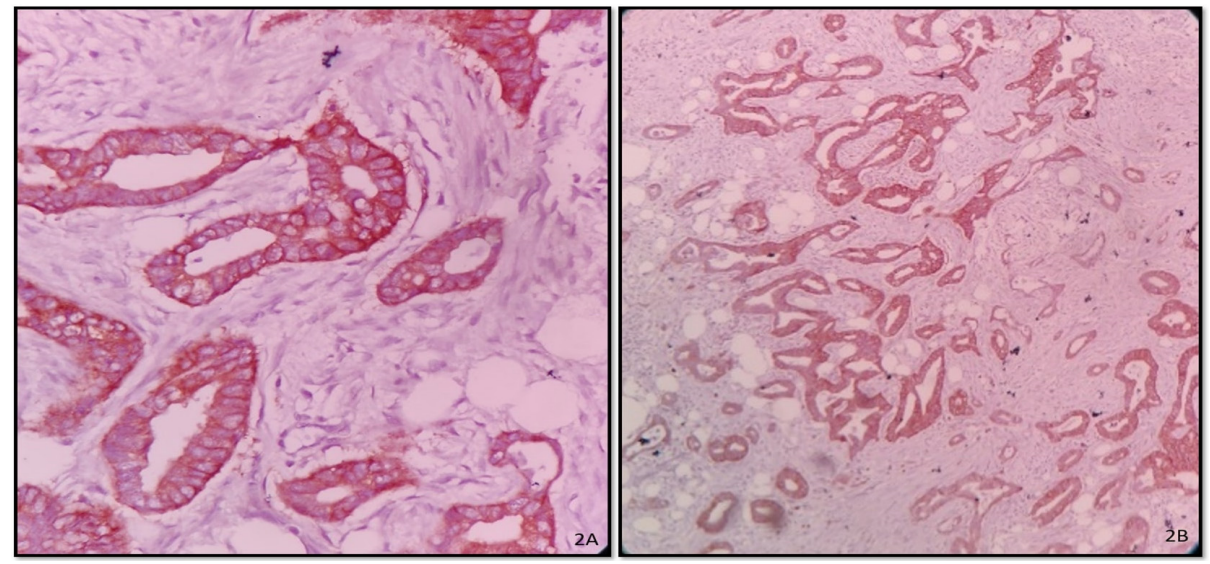

Figure 2. A, High Power Microphotograph of Well Differentiated Adenocarcinoma Gall Bladder Showing 2+ Positivity (EGFR, IHC 40X). B, Microphotograph of Moderately differentiated Adenocarcinoma gall bladder showing 3+ positivity (EGFR, IHC 10X).

to males worldwide [10]. Age-adjusted incidence of GBC among females in Delhi is 7.4 persons/100,000 populations per year. It is the fourth most common cancer among females after breast, cervix, and ovary [11].

In our study, the age ranged from 21 to 86 years with mean age of the patients being 55.9 years; $90 \%$ of the patients being females. The male: female ratio in our study was 1:9. In a recent study in a tertiary care hospital in New Delhi (2018), the mean age of the patients was 40.2 years (range 20-74 years) with 70\% females and 30\% males [12]. In another study by Hadi $\mathrm{R}$ et al [13] median age was 48 years, $83.33 \%$ were females; female predominance being similar to that seen in our study.

In different series of gallbladder cancers, stones have

Table 3. EGFR Association with Various Histopathological Parameters

\begin{tabular}{|c|c|c|c|c|c|c|}
\hline & & \multicolumn{2}{|c|}{$\begin{array}{l}\text { EGFR Positive } \\
\qquad(2+/ 3+)\end{array}$} & \multicolumn{2}{|c|}{$\begin{array}{c}\text { EGFR negative } \\
(0 / 1+)\end{array}$} & \multirow[t]{2}{*}{ p-value } \\
\hline & & No. & $\%$ & No. & $\%$ & \\
\hline \multirow[t]{5}{*}{ Histopathological type } & Conventional Adenocarcinoma & 23 & 57.5 & 11 & 27.5 & 0.613 \\
\hline & Papillary Adenocarcinoma & 1 & 2.5 & - & - & \\
\hline & Adenosquamous carcinoma & 1 & 2.5 & - & - & \\
\hline & Squamous cell carcinoma & 2 & 5 & - & - & \\
\hline & $\begin{array}{l}\text { Adenocarcinoma with } \\
\text { xanthogranulomatous cholecystitis }\end{array}$ & 2 & 5 & - & - & \\
\hline \multirow[t]{3}{*}{ Histologic Grade } & Well differentiated (G1) & 4 & 10 & 8 & 20 & 0.001 \\
\hline & Moderately differentiated (G2) & 20 & 50 & 3 & 7.5 & \\
\hline & Poorly differentiated (G3) & 5 & 12.5 & - & - & \\
\hline \multirow[t]{6}{*}{ Pathological Stage } & $\mathrm{T} 1 \mathrm{a}$ & 2 & 5 & 4 & 10 & 0.098 \\
\hline & $\mathrm{T} 1 \mathrm{~b}$ & 11 & 27.5 & 6 & 15 & \\
\hline & $\mathrm{T} 2$ & 10 & 25 & 1 & 2.5 & \\
\hline & $\mathrm{T} 2 \mathrm{~N} 1$ & 2 & 5 & - & - & \\
\hline & $\mathrm{T} 3$ & 3 & 7.5 & - & - & \\
\hline & T3N1 & 1 & 2.5 & - & - & \\
\hline \multirow[t]{2}{*}{ LN status ( $\mathrm{n}=16$ cases $)$} & Present & 3 & 18.7 & - & - & 1 \\
\hline & Absent & 10 & 62.6 & 3 & 18.7 & \\
\hline \multirow[t]{2}{*}{ Peri-neural Invasion ( $\mathrm{n}=40$ cases) } & Present & 7 & 17.5 & 1 & 2.5 & 0.405 \\
\hline & Absent & 22 & 55 & 10 & 25 & \\
\hline \multirow[t]{2}{*}{ Lymphovascular invasion ( $\mathrm{n}=40$ cases $)$} & Present & 11 & 27.5 & 1 & 2.5 & 0.124 \\
\hline & Absent & 18 & 45 & 10 & 25 & \\
\hline \multirow[t]{2}{*}{ Liver involvement ( $\mathrm{n}=11$ cases) } & Present & 3 & 27.3 & - & - & 1 \\
\hline & Absent & 6 & 54.5 & 2 & 18.2 & \\
\hline \multirow[t]{2}{*}{ Early and advanced stage cancer } & Early & 13 & 32.5 & 10 & 25 & 0.012 \\
\hline & Advanced & 16 & 40 & 1 & 2.5 & \\
\hline
\end{tabular}


Table 4. HER2/neu Association with Various Histopathological Parameters

\begin{tabular}{|c|c|c|c|c|c|c|}
\hline & & \multicolumn{2}{|c|}{$\begin{array}{c}\text { HER2/neu Positive } \\
\text { (2+/3+) }\end{array}$} & \multicolumn{2}{|c|}{$\begin{array}{l}\text { HER2/neu negative } \\
(0 / 1+)\end{array}$} & \multirow[t]{2}{*}{ p-value } \\
\hline & & No & $\%$ & No & $\%$ & \\
\hline \multirow[t]{5}{*}{ Histopathological type } & Conventional Adenocarcinoma & 11 & 27.5 & 23 & 57.5 & 0.434 \\
\hline & Papillary Adenocarcinoma & - & - & 1 & 2.5 & \\
\hline & Adenosquamous carcinoma & 1 & 2.5 & - & - & \\
\hline & Squamous cell carcinoma & 1 & 2.5 & 1 & 2.5 & \\
\hline & Adenocarcinoma with XGC & - & - & 2 & 5 & \\
\hline \multirow[t]{3}{*}{ Histological Grade } & Well differentiated (G1) & 9 & 22.5 & 3 & 7.5 & 0.0006 \\
\hline & Moderately differentiated (G2) & 4 & 10 & 19 & 47.5 & \\
\hline & Poorly differentiated (G3) & - & - & 5 & 12.5 & \\
\hline \multirow[t]{6}{*}{ Pathological Stage } & T1a & 3 & 7.5 & 3 & 7.5 & 0.435 \\
\hline & $\mathrm{T} 1 \mathrm{~b}$ & 5 & 12.5 & 12 & 30 & \\
\hline & $\mathrm{T} 2$ & 3 & 7.5 & 8 & 20 & \\
\hline & $\mathrm{T} 2 \mathrm{~N} 1$ & 1 & 2.5 & 1 & 2.5 & \\
\hline & $\mathrm{T} 3$ & - & - & 3 & 7.5 & \\
\hline & T3N1 & 1 & 2.5 & - & - & \\
\hline \multirow[t]{2}{*}{ LN status ( $\mathrm{n}=16$ cases) } & Present & 2 & 12.5 & 1 & 6.3 & 0.136 \\
\hline & Absent & 2 & 12.5 & 11 & 68.7 & \\
\hline \multirow[t]{2}{*}{ Perineural Invasion ( $\mathrm{n}=40$ cases) } & Present & 4 & 10 & 4 & 40 & 0.4 \\
\hline & Absent & 9 & 22.5 & 23 & 57.5 & \\
\hline \multirow[t]{2}{*}{ Lymphovascular invasion ( $n=40$ cases) } & Present & 4 & 10 & 8 & 20 & 1 \\
\hline & Absent & 9 & 22.5 & 19 & 47.5 & \\
\hline \multirow[t]{2}{*}{ Liver involvement ( $\mathrm{n}=11$ cases) } & Present & 2 & 18.2 & 1 & 9.1 & 0.152 \\
\hline & Absent & 1 & 9.1 & 7 & 17.5 & \\
\hline \multirow[t]{2}{*}{ Early and advanced stage cancer } & Early & 15 & 37.5 & 8 & 20 & 0.72 \\
\hline & Advanced & 12 & 30 & 5 & 12.5 & \\
\hline
\end{tabular}

been reported in 60 to $93 \%$ of cases and a high proportion of patients had long-term symptoms of cholelithiasis before discovery of tumor [14-17]. Gallbladder cancer and gallstones share common epidemiological characteristics. Similarly, in our study, gallstone disease was seen in $100 \%$ of the cases on ultrasonography. However only $87.5 \%$ of the patients showed stones on gross examination as rest of the stones were handed over to the patients' attendants at the time of surgery.

Histopathologically, Conventional Adenocarcinoma was the most common subtype present in our study in $85 \%$ of the cases. Papillary Adenocarcinoma and Adenosquamous carcinoma both constituted $2.5 \%$ of the cases. This was similar to a study by Ashai F et al, [18] in which most of the cases (98\%) were adenocarcinoma and only $2 \%$ were adenosquamous carcinoma. In a study by Neyaz et al, out of 268 cases studied, 221 cases were that of conventional adenocarcinoma, 23 invasive papillary carcinoma, 11 mucinous adenocarcinoma, 8 adenosquamous, 1 signet ring, 3 neuroendocrine and 1 undifferentiated carcinoma [19]. So, adenocarcinoma was the most common histopathological type seen in almost all studies on GBC.

The over-expression of markers such as EGFR and HER2/neu may have direct clinical implications with an alternative strategy for the management of gallbladder carcinoma. Our study showed EGFR expression in $72.5 \%$ of GBC cases. The range of EGFR expression varies in the literature from $34.6 \%$ by Neyaz A et al, [19] $50 \%$ by Martins et al, [20], $88 \%$ by Kumar N et al, [21] to $100 \%$ by Chang PY et al [22].

We used the CAP/ASCO grading system for breast cancer for EGFR immune expression. However, there is no well-defined standard criteria for interpretation of EGFR immunostaining. In our study, EGFR expression showed a significant association with tumor grade $(\mathrm{P}<0.05)$; i.e. Well differentiated carcinoma cases were predominantly negative for EGFR; Moderately differentiated cases were predominantly positive for EGFR and all cases of Poorly differentiated carcinoma were positive for EGFR. (Figure 2) So, a significant increase in EGFR expression was observed on increase in grade of GBC $(\mathrm{P}=0.001)$. However, there was no significant association of EGFR expression with tumor stage, histopathology diagnosis, perineural Invasion, lymphovascular invasion, LN status and liver involvement. $(\mathrm{P}>0.05)$. However, Kumar $\mathrm{N}$ et al [22] reported that with decrease in differentiation of tumor, EGFR immunostaining intensity increased $(\mathrm{P}=0.0001)$. Our results are at par with study by Neyaz et al., [20] who found no significant association of EGFR expression with tumor stage, histopathology diagnosis, perineural invasion, lymphovascular invasion, LN status 

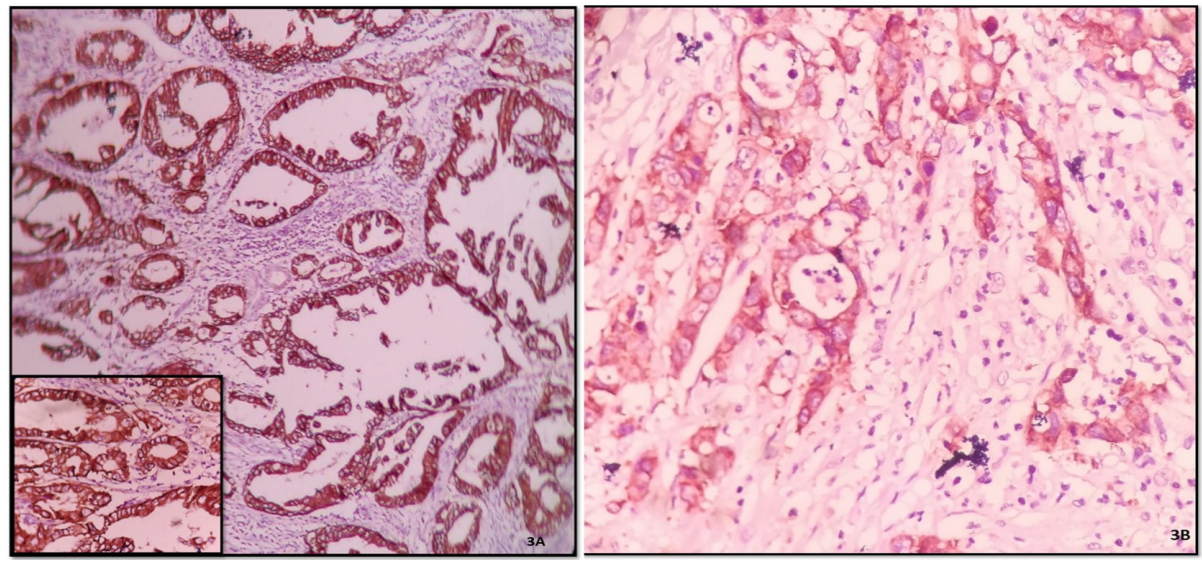

Figure 3. A, Microphotograph of Well Differentiated Adenocarcinoma Gall Bladder Showing 3+ Positivity (HER2/ neu, IHC 10X); B, Microphotograph of Moderately differentiated Adenocarcinoma gall bladder showing $2+$ positivity (HER2/neu, IHC 40X)

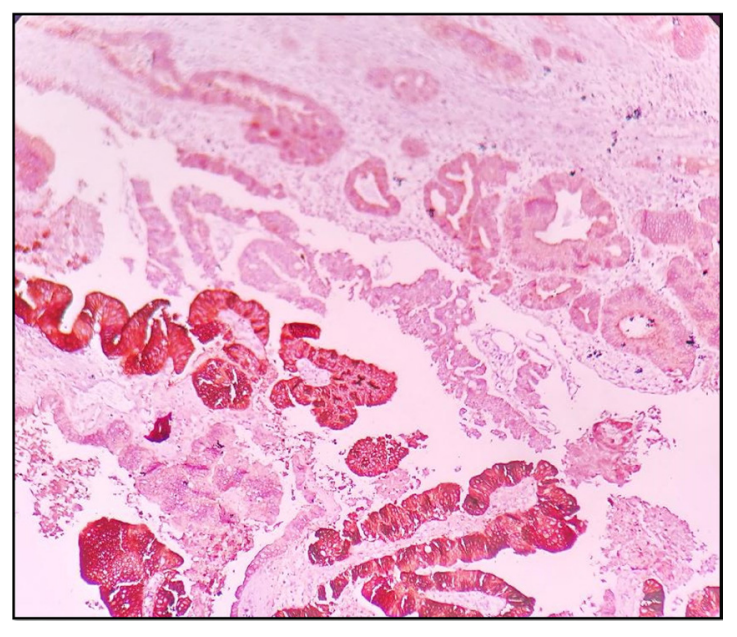

Figure 4. Intratumoral HER2/neu Heterogeneity Seen in a Case of Well Differentiated Adenocarcinoma Gall Bladder. The HER2/neu by IHC shows weak positivity (score $1+$ ) in the upper part while strong positivity (score $3+$ ) is seen in lower part of the microphotograph (HER2/ neu, IHC 10X)

and liver involvement was observed; however, they found no significant association of EGFR expression with increase in grade of GBC which is in contrast to our study $(\mathrm{P}>0.05)$. Similarly, Zhou et al., [23] reported that EGFR high expression was not associated with the parameters, such as age, gender, TNM stage, differentiation, or lymph node status.

HER2/neu (Erb B-2) overexpression in breast cancer has been associated with increased disease recurrence and worse prognosis. Its overexpression is also seen in ovarian cancer, stomach cancer, and uterine serous endometrial carcinoma. There are few but conflicting reports dealing with the clinical significance of HER2/neu expression in GBC, [24] thus our study holds importance in this aspect.

We used the CAP/ASCO scoring criteria established for breast cancer in reporting the IHC results. In our study, HER2/neu positivity of $32.5 \%$ ( 13 cases) was seen in GBC cases which was higher than that reported by Roa I et al., who found HER2/neu overexpression in $14 \%$ cases [25].
In both the studies similar reference criteria were used. This underscores the need for establishing a standard uniform scoring system methodology for reporting HER2/ neu overexpression by IHC in gall bladder. HER2/neu overexpression in GBC reported by Neyaz et al.,[20] Singh et al., [26] and Hadi R et al.,[14] were 27.3\%, 36.67\%, and $66.67 \%$, respectively which was comparable or higher than our study.

In our study, HER2/neu expression showed a significant association with tumor grade $(\mathrm{P}<0.05)$; i.e. Well differentiated carcinoma cases were predominantly positive for HER2/neu. The correlation of HER2/neu overexpression with stage and grades of tumour have shown varying results in previous reports. Similar to the findings of our study Chaube et al. (2006), [27] observed a trend of decrease in HER2/neu expression with increasing grade of tumor but the results were not statistically significant which was unlike our study where a statistically significant association was seen. Puhalla et al. (2007) [28] observed that HER2/neu overexpression correlated with advanced tumor stage which was not in accordance with our study.

From our study results, the fact that HER2/neu expression were found more in better differentiated tumour and early cancers may suggest a possible role of HER2/neu as an early event in the carcinogenesis of

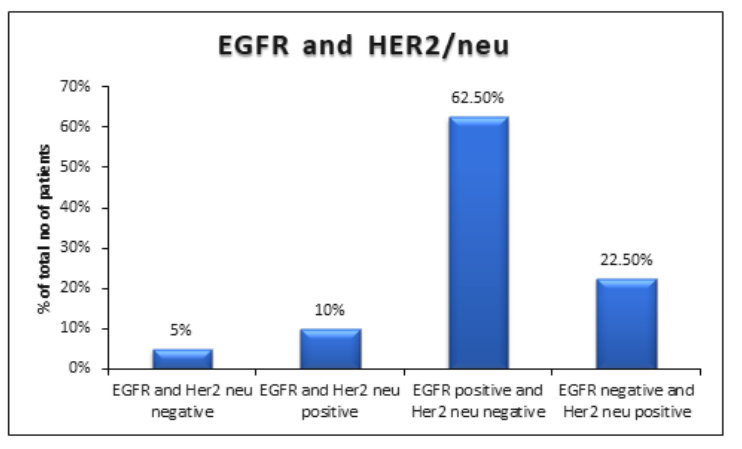

Figure 5. Association of EGFR and HER2/neu Expression 
gallbladder cancer. The wide variation could be due to the different scoring systems adopted by different authors. This highlights the need to evolve a uniform consensus on scoring for HER2/neu staining in gall bladder cancers on similar lines as breast cancer. HER2/neu is an attractive target also because we now have several drugs which could inhibit HER2/neu for anti-cancer effect with successes seen in the treatment of breast and gastric cancer [29]. An anti-HER2/neu agent, lapatinib, when combined with gemcitabine, had a synergistic anti-proliferative effect on a GBC cell line (TGBC1-TKB) in vitro [30].

In the present study, the immunoexpression of EGFR was inversely related with HER2/neu expression and this association was statically significant. (Figure 5) However, Doval et al. [31] found no such significant association of EGFR with HER2/neu $(\mathrm{P}=1.000)$. Hadi et al.,[13] reported high positivity of both EGFR and HER2/neu in GBC cases with a positive correlation between them, but they mentioned that large numbers of patients are required for better and consistent results in their setup. Thus we see that EGFR and HER2/neu positivity correlate with tumor grade and thus the targeted treatment can be helpful in increasing the overall survival of the patients.

In conclusion, to conclude, in our study overexpression of EGFR and HER2/neu was seen in $72.5 \%$ and $32.5 \%$ cases of GBC respectively suggesting that altered expression of these genes maybe a possible mechanism in gallbladder carcinogenesis. Furthermore, EGFR expression was significant in poorly differentiated or advanced stage cancers while HER2/neu expression was seen in well differentiated gall bladder carcinomas thus providing rationale to further explore the use of anti-EGFR and anti-HER2/neu therapy in gallbladder cancer.

\section{References}

1. Randi G, Franceschi S, La Vecchia C. Gallbladder cancer worldwide: Geographical distribution and risk factors. International Journal of Cancer. 200604 01;118(7):15911602. https://doi.org/10.1002/ijc.21683

2. Nemunaitis JM, Brown-Glabeman U, Soares H, Belmonte J, Liem B, Nir I, Phuoc V, Gullapalli RR. Gallbladder cancer: review of a rare orphan gastrointestinal cancer with a focus on populations of New Mexico. BMC Cancer. 201806 18;18(1). https://doi.org/10.1186/s12885-018-4575-3

3. Shaffer EA. Gallbladder cancer: the basics. Gastroenterol Hepatol (N Y). 2008;4:737-41.

4. Zhu AX, Hong TS, Hezel AF, Kooby DA. Current Management of Gallbladder Carcinoma. The Oncologist. 2010 02;15(2):168-181. https://doi.org/10.1634/ theoncologist.2009-0302

5. Maurya SK, Tewari M, Mishra RR, Shukla HS. Genetic abberations in gallbladder cancer. Surgical Oncology. 2012 03;21(1):37-43. https://doi.org/10.1016/j. suronc. 2010.09.003

6. Hezel AF, Deshpande V, Zhu AX. Genetics of Biliary Tract Cancers and Emerging Targeted Therapies. Journal of Clinical Oncology. 201007 20;28(21):3531-3540. https:// doi.org/10.1200/jco.2009.27.4787

7. Gonzalez R. Pathologic TNM staging of carcinomas of the gallbladder and cystic duct. PathologyOutlines. comwebsite.https://www.pathologyoutlines.com/topic/ gallbladderstaging.html. Accessed October 9th, 2019.

8. Wolff AC, Hammond MEH, Allison KH, Harvey BE, Mangu PB, Bartlett JM, Bilous M, Ellis IO, Fitzgibbons P, Hanna W, Jenkins RB, Press MF, Spears PA, Vance GH, Viale G, McShane LM, Dowsett M. Human Epidermal Growth Factor Receptor 2 Testing in Breast Cancer: American Society of Clinical Oncology/College of American Pathologists Clinical Practice Guideline Focused Update. Journal of Clinical Oncology. 201807 10;36(20):2105-2122. https:// doi.org/10.1200/jco.2018.77.8738

9. Bray F, Ferlay J, Soerjomataram I, Siegel RL, Torre LA, Jemal A. Global cancer statistics 2018: GLOBOCAN estimates of incidence and mortality worldwide for 36 cancers in 185 countries. CA: A Cancer Journal for Clinicians. 2018 09 12;68(6):394-424. https://doi.org/10.3322/caac.21492

10. Konstantinidis IT. Trends in Presentation and Survival for Gallbladder Cancer During a Period of More Than 4 Decades. Archives of Surgery. 200905 18;144(5):441. https://doi.org/10.1001/archsurg.2009.46

11. Consolidated ICMR report of Population Based Cancer Registries in the year 2001- 2004. http://www.icmr.nic.in/ ncrp/report_pop_200104/cancer_p_based.htm).

12. Jha V, Sharma P, Mandal KA. Incidental gallbladder carcinoma: Utility of histopathological evaluation of routine cholecystectomy specimens. South Asian Journal of Cancer. 2018 01;07(01):21-23. https://doi.org/10.4103/2278330x.226802

13. Hadi R, Pant M, Husain N, Singhal A, Khurana R, Agarwal G, et al. EGFR and HER-2/neu Expression in Gallbladder Carcinoma: An Institutional Experience. Gulf J Oncolog. 2016;1:12-9.

14. Hart J, Modan B, Shani M. CHOLELITHIASIS IN THE ÆTIOLOGY OF GALLBLADDER NEOPLASMS. The Lancet. 1971 06;297(7710):1151-1153. https://doi. org/10.1016/s0140-6736(71)91661-8

15. Perpetuo MDCMO, Valdivieso M, Heilbrun LK, Nelson RS, Connor T, Bodey GP. Natural history study of gallbladder cancer.A review of 36 years experience at M. D. Anderson hospital and tumor institute. Cancer. 1978 07;42(1):330-335. https://doi.org/10.1002/1097-0142(197807)42:1<330::aidcncr2820420150>3.0.co;2-f

16. Black WC, Key CR, Carmany TB, Herman D. Carcinoma of the gallbladder in a population of Southwestern American Indians. Cancer. 1977 03;39(3):1267-1279. https://doi.org/10.1002/1097-0142(197703)39:3<1267::aidcncr $2820390338>3.0$. co; $2-0$

17. Diehl A. Gallstone size and risk of gallbladder cancer. J Amer Med Ass. 1983;250:2323-6.

18. Ashai F, Ashraf A, Rashid A, Banday BM, Bhalla S, Dhawan S. Expression of Her2/neu receptor in Carcinoma Gallbladder correlates significantly with advanced tumor stage. International Journal of Hepatobiliary and Pancreatic Diseases. 2015;5:86. https://doi.org/10.5348/ijhpd-201540-cr-15

19. Neyaz A, Husain N, Gupta S, Kumari S, Arora A, Awasthi NP, Malhotra KP, Misra S. Investigation of targetable predictive and prognostic markers in gallbladder carcinoma. Journal of Gastrointestinal Oncology. 2018 02;9(1):111-125. https:// doi.org/10.21037/jgo.2017.10.02

20. Martins SJ, Pais-Costa SR, Artigiani-Neto R, Farah JFDM, Franco MIF, Goldemberg A. Epidermal growth factor receptor (EGFR) status and prognosis in gallbladder cancer.. Journal of Clinical Oncology. 201205 20;30(15_suppl):e14657-e14657. https://doi.org/10.1200/ jco.2012.30.15_suppl.e14657

21. Kumar N, Kumar N, Khan M, Rigvardhan, Ranjan R, Hazra 
N. Epidermal growth factor receptor expression in carcinoma gallbladder: A prospective study in Indian scenario. Journal of Cancer Research and Therapeutics. 2016;12(2):959. https://doi.org/10.4103/0973-1482.179063

22. Chang P, Cheng M, Lee H, Hsieh C, Yao N. Preliminary Experience of Cetuximab in the Treatment of AdvancedStage Biliary Tract Cancer. Onkologie. 2010;33(1-2):11-11. https://doi.org/10.1159/000264613

23. Fan L, Zhou W, Jiang C, Zhan N, Lv X, Ninu M. Human epidermal growth factor receptor 2, epidermal growth factor receptor, and c-MET overexpression and survival in biliary tract cancer: A meta-analysis. Journal of Cancer Research and Therapeutics. 2018;14(8):28. https://doi. org/10.4103/0973-1482.206864

24. Ooi A, Suzuki S, Nazakawa K, Itakura J, Imoto I, Nakamura $\mathrm{H}$, et al. Gene amplification of Myc and its coamplification with ERBB2 and EGFR in gallbladder adenocarcinoma . Anticancer Res. 2009;29:19-26.

25. Roa I, de Toro G, Schalper K, de Aretxabala X, Churi C, Javle M. Overexpression of the HER2/neu gene: A new therapeutic possibility for patients with advanced gallbladder cancer. Gastrointest Cancer Res. 2014;7:42-8.

26. Singh A, Mishra PK, Saluja SS, Talikoti MA, Kirtani P, Najmi AK. Prognostic Significance of HER-2 and p53 Expression in Gallbladder Carcinoma in North Indian Patients. Oncology. 2016;91(6):354-360. https://doi. org/10.1159/000450999

27. Chaube A, Tewari M, Garbyal R, Singh U, Shukla HS. Preliminary study of p53 and c-erbB-2 expression in gallbladder cancer in Indian patients. BMC Cancer. 200605 10;6(1). https://doi.org/10.1186/1471-2407-6-126

28. Puhalla H, Wrba F, Kandioler D, Lehnert M, Huynh A, Gruenberger T, et al. Expression of p21(Wafl/Cip1), p57(Kip2) and HER2/neu in patients with gallbladder cancer. Anticancer Res. 2007;27:1679-84.

29. Pignochino Y, Sarotto I, Peraldo-Neia C, Penachioni JY, Cavalloni G, Migliardi G, Casorzo L, Chiorino G, Risio M, Bardelli A, Aglietta M, Leone F. Targeting EGFR/HER2 pathways enhances the antiproliferative effect of gemcitabine in biliary tract and gallbladder carcinomas. BMC Cancer. 2010 Nov 18;10(1). https://doi.org/10.1186/1471-240710-631

30. Ramanathan RK, Belani CP, Singh DA, Tanaka M, Lenz H, Yen Y, Kindler HL, Iqbal S, Longmate J, Mack PC, Lurje G, Gandour-Edwards R, Dancey J, Gandara DR. A phase II study of lapatinib in patients with advanced biliary tree and hepatocellular cancer. Cancer Chemotherapy and Pharmacology. 200901 24;64(4):777-783. https://doi. org/10.1007/s00280-009-0927-7

\section{(ब) $\odot$}

This work is licensed under a Creative Commons AttributionNon Commercial 4.0 International License. 